\title{
Postoperative mortality and complications after radical cystectomy for bladder cancer in Quebec: A population-based analysis during the years 2000-2009
}

\author{
Ahmed S. Zakaria, MD, MSc; Fabiano Santos, PhD; Alice Dragomir, PhD; Simon Tanguay, MD, FRCSC; \\ Wassim Kassouf, MD, FRCSC; Armen G. Aprikian, MD, FRCSC
}

Department of Surgery, Division of Urology, McGill University, Montreal, QC

Cite as: Can Urol Assoc J 2014;8(7-8):259-67. http://dx.doi.org/10.5489/cuaj.1997

Published online August 11, 2014.

\section{Abstract}

Introduction: Radical cystectomy $(\mathrm{RC})$ is a very complex urologic procedure. Despite improvements in practice, technique and process of care, it is still associated with significant complications, including death, with reported postoperative mortality rates ranging from $0.8 \%$ to $8 \%$. We examine the quality of surgical care indicators and document the mortality rates at 30,60 and 90 days after RC across Quebec.

Methods: Within the Régie de I'assurance maladie du Québec (RAMQ) administrative database (this database provides prospectively collected universal data on all medical services) and the Institut de la statistique du Québec (ISQ) database (this provides vital status data), we used procedure codes to identify patients who underwent RC for bladder cancer in Quebec over 10 years (between 2000 and 2009), as well as RC outcomes and dates of death. Data obtained were retrospectively analyzed in relation to multiple parameters, including patient characteristics and healthcare providers' volumes. The outcomes analyzed included postoperative complications and mortality rates at 30,60 and 90 days. Results: A total of 2778 RC were performed in 48 hospitals by 122 urologists across Quebec. Among them, 851 (30.6\%) patients had at least one postoperative complication and $350(12.6 \%)$ patients had more than one complication. The overall mortality rates at 30 , 60 and 90 days were $2.8 \%, 5.3 \%$ and $7.5 \%$, respectively, with significantly elevated 90-day mortality rates in some centres. In the multivariate analysis, increased age was associated with increased risk of post-RC complications and mortality. For example, patients over 75 had more chance of having at least one postoperative complication (odds ratio [OR] 1.66, 95\% confidence interval [CI]: 1.31-2.11) and mortality at 90 days (OR 3.28, 95\% Cl: 2.05-5.26). Provider volume effect on outcomes was statistically significant, with large hospitals having decreased risk of 30-day mortality (OR 0.29, 95\% Cl: 0.12-0.70), 60-day mortality (OR 0.41, 95\% Cl: $0.26-0.82$ ) and 90-day mortality (OR 0.52, 95\% Cl: 0.29-0.93) when compared to smaller hospitals. Surgeon volume showed weak, but not statistically significant, evidence of reduced odds of mortality for the high-volume surgeon. Limitations to our study include reliance on administrative data, which lack some relevant clinical information (such as patient functional status and tumour pathological characteristics) to perform risk adjustment analysis. Conclusion: Our study demonstrates that postoperative outcomes after RC in Quebec varies based on several parameters. In addition, 30-day postoperative mortality after RC in Quebec appears acceptable. However, 90-day postoperative mortality rates remain significantly elevated in some centres, particularly in the elderly. This requires further research.

\section{Introduction}

Urinary bladder cancer (BC) is common in North America and is the second most frequent genitourinary tract tumour in terms of incidence and mortality. ${ }^{1,2}$

Radical cystectomy (RC) and urinary diversion are the gold standard treatments for muscle-invasive urinary BC, as well as for some non-muscle invasive disease. These treatments are also the most extensive urologic surgical procedures. Despite improvements in practice, technique and process of care, RC is still associated with significant complications, including death, with wide variability in reported postoperative morbidity and mortality rates ranging from $19 \%$ to $64 \%$ and $0.8 \%$ to $8.3 \%$, respectively. 5,6

Quality of care delivered patients undergoing $\mathrm{RC}$ is a subject that has drawn much attention during recent years and many attempts have been made to identify and validate the processes of care to improve outcomes. ${ }^{7}$ During the last 3 decades, many studies have examined the association between postoperative outcomes and volume of services provided by healthcare facilities. ${ }^{8}$ Recently, with the availability of population-based large databases allowing the study of RC outcomes, ${ }^{9-12}$ many studies (but not all) have suggested that lower morbidity and mortality rates are associated with higher hospital and surgeon volume.

The aim of our study was to examine the quality of surgical care delivered to urinary BC patients undergoing RC 
in Quebec during 2000 and 2009, by assessing the related indicators and measuring postoperative mortality rates at 30, 60 and 90 days.

\section{Methods}

We conducted a retrospective cohort study using data of patients who underwent RC for urinary BC in Quebec between 2000 and 2009. The cohort was built by linking two administrative databases: the Régie de l'assurance maladie du Québec (RAMQ), and the Fichier des événements démographiques de I'Institut de la statistique du Québec (ISQ). The RAMQ is the government body that administers the province's health matters. All healthcare services are recorded in the RAMQ administrative databases, which are comprised by a set of claims files. The RAMQ database medical claim file provides information on medical services dispensed to all Quebec residents. This database provides data on physician-based diagnoses (International Classification of Diseases, ninth revision, ICD-9), relevant therapeutic procedures and its calendar date, characteristics of the patient, healthcare providers, and the costs involved. RAMQ does not collect information on disease stage, grade, patient functional status or comorbidities. The ISQ administers the Fichier des événements démographiques that provides demographic data on all births and deaths in Quebec.

The linkage between RAMQ and ISQ data is possible using a patient's anonymous identifier (generated from the Numéro d'assurance maladie [NAM], a unique identifier for all legal residents of Quebec). The use of the data was approved by the Comission de l'acces a l'information (CAI) of Quebec, the provincial agency that grants authorization for the use of linked administrative databases.

To be included in the study, patients must have undergone a RC for urinary $\mathrm{BC}$, and also have medical services data available for the 2-year period preceding the RC.
Patients were selected from January 1, 2000 until September 30,2009 . The index date is the date at which each patient entered the cohort (calendar date of the RC). Exclusion criteria were: patients under 35 years old and patients whose RC was preceded by neoadjuvant treatments. We determined the following 2 outcomes as quality of surgery indicators: (1) the presence of postoperative complications from admission to 90 days following RC (urinary tract complications, gastrointestinal (GI) tract complications and wound complications) and (2) postoperative mortality rates at 30,60 and 90 days. Standardized provincial procedure act codes were used to identify these complications within the RAMQ database.

Potential predictors for quality of surgery after RC were divided into two groups of variables (Table 1).

Descriptive statistics were used to summarize the characteristics of the study population, observed outcomes and predictors. The relationship between each quality of surgery indicator and its potential predictors was analyzed with graphical and Kruskall-Wallis test. Predictors for postoperative complications were analyzed separately for the group, and also for the individual complications. Multivariate unconditional logistic regression models were used to generate odds ratio (OR) along with $95 \%$ confidence intervals $(95 \% \mathrm{Cl})$. This modelling allows us to adjust for correlations within each unit of observation (each patient) so we can account for the fact that each patient could have had more than one complication at different times. All analyses were two-sided, with $p \leq 0.05$ being considered significant. SAS 9.3 (SAS Institute Inc., Cary, NC) was used to conduct the calculations.

\section{Results}

The preliminary cohort included 2988 patients who underwent RC in Quebec from January 1, 2000 to September 30, 2009. Our final cohort included 2778 patients, after

\footnotetext{
Table 1. Potential predictors for quality of surgery after radical cystectomy divided into 2 groups of variables

Group 1: Variables related to the patient Age: 4 categories $(<60$; between 60-69; between 70-75; $>75)$
Gender: dichotomous

Group 2: Variables related to the healthcare system (hospital and surgeon volume)*

Hospitals with urology residency training program: dichotomous (academic and nonacademic)

Hospital annual RC caseload: 3 categories (hospitals performing $<10 \mathrm{RC} /$ year; between 10-25 RC/year; >25 RC/year) according to average number of RC performed per year over the study period with minimum of $1 \mathrm{RC} /$ year, maximum of $41.4 \mathrm{RC} /$ year and median of $12.6 \mathrm{RC} /$ year

Hospital number of beds: 3 categories (small hospitals with up to 200 beds; medium hospitals with $200-500$ beds; large hospitals with more than 500 beds) with a mean of 421 beds, median of 405 beds (SD: 190)

Surgeons' annual RC caseload: dichotomous (surgeons who perform less than $5 \mathrm{RC}$ / year and surgeons who perform 5 and more than $5 \mathrm{RC} /$ year) according to average number of $\mathrm{RC}$ performed per year over whole study period with minimum of $1 \mathrm{RC} /$ year, maximum of $15 \mathrm{RC} /$ year and median of $2.5 \mathrm{RC} /$ year 
Table 2. Baseline characteristics of the study population and the measured outcomes

\begin{tabular}{lcc}
\hline & Frequency & Percent \\
\hline Gender & & \\
\hline Male & 2095 & $75.41 \%$ \\
Female & 683 & $24.59 \%$ \\
\hline Age & & 60.44 \\
\hline$<60$ years & 638 & $22.97 \%$ \\
Between 60-69 years & 823 & $29.63 \%$ \\
Between 70-75 years & 573 & $20.63 \%$ \\
$>75$ years & 744 & $26.78 \%$ \\
\hline Postoperative complications & & \\
\hline At least 1 complication & 851 & $30.63 \%$ \\
More than 1 & 350 & $12.59 \%$ \\
complication & & \\
Urinary tract & 497 & $17.89 \%$ \\
complications & 155 & $5.58 \%$ \\
Wound complications & 128 & $4.61 \%$ \\
Gl tract complications & 78 & $2.81 \%$ \\
Mortality at 30 days & 146 & $5.26 \%$ \\
Mortality at 60 days & 207 & $7.45 \%$ \\
Mortality at 90 days & & \\
\hline Gl: gastrointestinal. & &
\end{tabular}

excluding 210 patients (7\% of the original study population) who had neoadjuvant chemotherapy treatment (neoadjuvant treatment was identified anytime between the date of the patient's first transurethral resection of the bladder tumour and the date of the RC).

We noted the baseline characteristics of the study population and the measured outcomes (Table 2). Males formed
$75.4 \%(n=2095)$ of the cohort, $29.6 \%(n=823)$ of patients were between 60 and 69 at the time of the RC, followed by patients over 75 who formed $26.7 \%(n=744)$. Overall during the study period, $30.6 \%(n=851)$ had at least one postoperative complication, while $12.5 \%(\mathrm{n}=350)$ had more than one complication. The vast majority of complications were related to the urinary tract; $17.8 \%(n=497)$ had at least 1 postoperative urinary tract complication at any time after RC (with $10.9 \%$ of patients $n=305$ ] having obstructive uropathy). Within 90 days of the RC, $10.7 \%$ $(\mathrm{n}=298)$ had urinary tract complications; $5.4 \%$ of patients $(n=150)$ required percutaneous nephrostomy tube insertion, $5 \%(n=141)$ had percutaneous collection drainage for urinomas and $0.25 \%(n=7)$ had total nephrectomy. Wound complications ranked second, where in the first 90 days following RC, $5.5 \%$ of patients $(n=155)$ needed surgical intervention to deal with these complications (mainly wound dehiscence). Of all the patients, $4.6 \%(n=128)$ had Gl tract complications in the first 90 days that needed surgical interventions in the form of exploratory laparotomies, revision of anastamoses or bowel exteriorization surgeries (iliostomies and colostomies).

The highest number of RCs cases were performed in 2005 $(n=299)$, while the highest rate of complications $(35.6 \%)$ occurred in 2006 and declined afterwards with a statistically significant trend ( $p=0.031$ ) (Fig. 1). Of note, the reason for the lower number of RCs in 2009 is due to the fact that only 9 months of data were available.

The postoperative mortality rates at 30, 60 and 90 days were $2.8 \%, 5.3 \%$ and $7.5 \%$, respectively; the highest mortal-

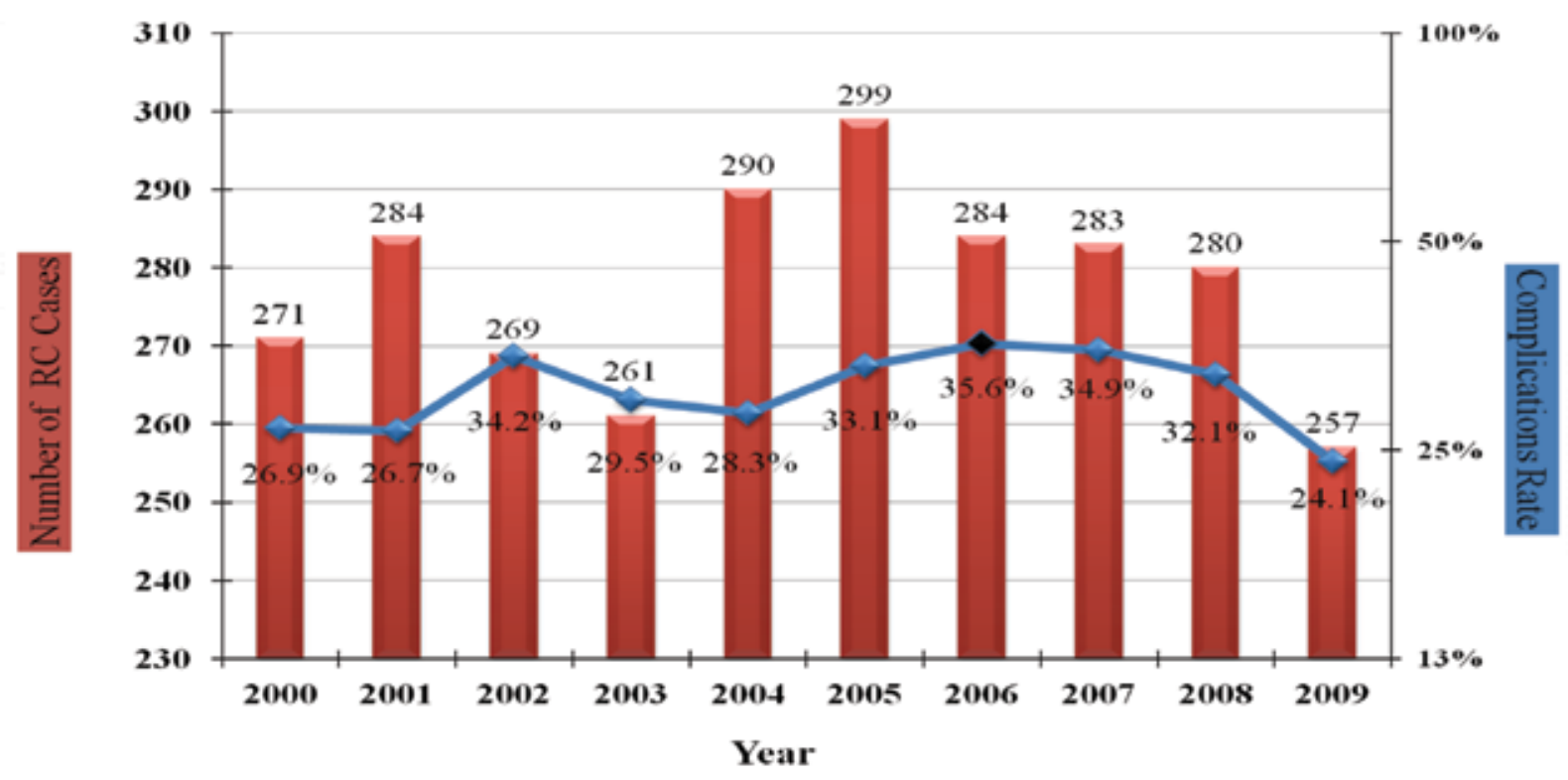

$\triangle$ Number of RC Cases $\leadsto$ Complications Rate

Fig. 1. Rate of radical cystectomy (RC) and postoperative complications over the whole study period. 


\begin{tabular}{|c|c|c|c|c|c|c|c|c|}
\hline & Age groups & $\begin{array}{c}\text { Frequency } \\
\text { of RC }\end{array}$ & $\begin{array}{l}\text { Mortality } \\
30 \text { days } \\
\text { frequency }\end{array}$ & $\begin{array}{c}\text { Mortality } \\
30 \text { days } \%\end{array}$ & $\begin{array}{l}\text { Mortality } \\
60 \text { days } \\
\text { frequency }\end{array}$ & $\begin{array}{l}\text { Mortality } \\
60 \text { days } \%\end{array}$ & $\begin{array}{l}\text { Mortality } \\
90 \text { days } \\
\text { frequency }\end{array}$ & $\begin{array}{l}\text { Mortality } \\
\mathbf{9 0} \text { days } \%\end{array}$ \\
\hline 1 & From 35 to 39 years & 25 & 1 & $4 \%$ & 1 & $4 \%$ & 1 & $4 \%$ \\
\hline 2 & From 40 to 44 years & 48 & 0 & $0 \%$ & 0 & $0 \%$ & 0 & $0 \%$ \\
\hline 3 & From 45 to 49 years & 110 & 0 & $0 \%$ & 1 & $0.9 \%$ & 4 & $3.63 \%$ \\
\hline 4 & From 50 to 54 years & 166 & 3 & $1.80 \%$ & 4 & $2.4 \%$ & 8 & $4.81 \%$ \\
\hline 5 & From 55 to 59 years & 289 & 4 & $1.38 \%$ & 6 & $2.07 \%$ & 11 & $3.8 \%$ \\
\hline 6 & From 60 to 64 years & 367 & 4 & $1.08 \%$ & 9 & $2.45 \%$ & 15 & $4.08 \%$ \\
\hline 7 & From 65 to 69 years & 456 & 9 & $1.97 \%$ & 18 & $3.94 \%$ & 29 & $6.35 \%$ \\
\hline 8 & From 70 to 74 years & 573 & 26 & $4.53 \%$ & 42 & $7.32 \%$ & 56 & $9.77 \%$ \\
\hline 9 & From 75 to 79 years & 469 & 15 & $3.19 \%$ & 38 & $8.1 \%$ & 47 & $10.02 \%$ \\
\hline \multirow[t]{2}{*}{10} & More than 80 years & 275 & 16 & $5.81 \%$ & 27 & $9.81 \%$ & 36 & $13.09 \%$ \\
\hline & Overall & 2778 & 78 & $2.81 \%$ & 146 & $5.25 \%$ & 207 & $7.45 \%$ \\
\hline
\end{tabular}

ity rate was in the 80 age group, where mortality rates were $5.8 \%, 9.8 \%$ and $13 \%$ at 30,60 and 90 days, respectively (Table 3). In addition, there was significant variation in the 90-day postoperative mortality rates across Quebec when sorted by hospitals (Fig. 2). Also the 30-day mortality rates varied significantly when compared to the previous decade (Fig. 3).
Descriptive statistics for the quality of surgery predictors are shown in Table 4. All patients had their RCs performed in 48 hospital facilities by 122 urologists across Quebec. Of these hospital facilities, 7 (hospitals with residency training programs) performed $42.3 \%(n=1175)$ of the cases, while the remaining 41 non-academic hospitals (hospitals without residents) performed $57.7 \%(n=1603)$ of the cases.

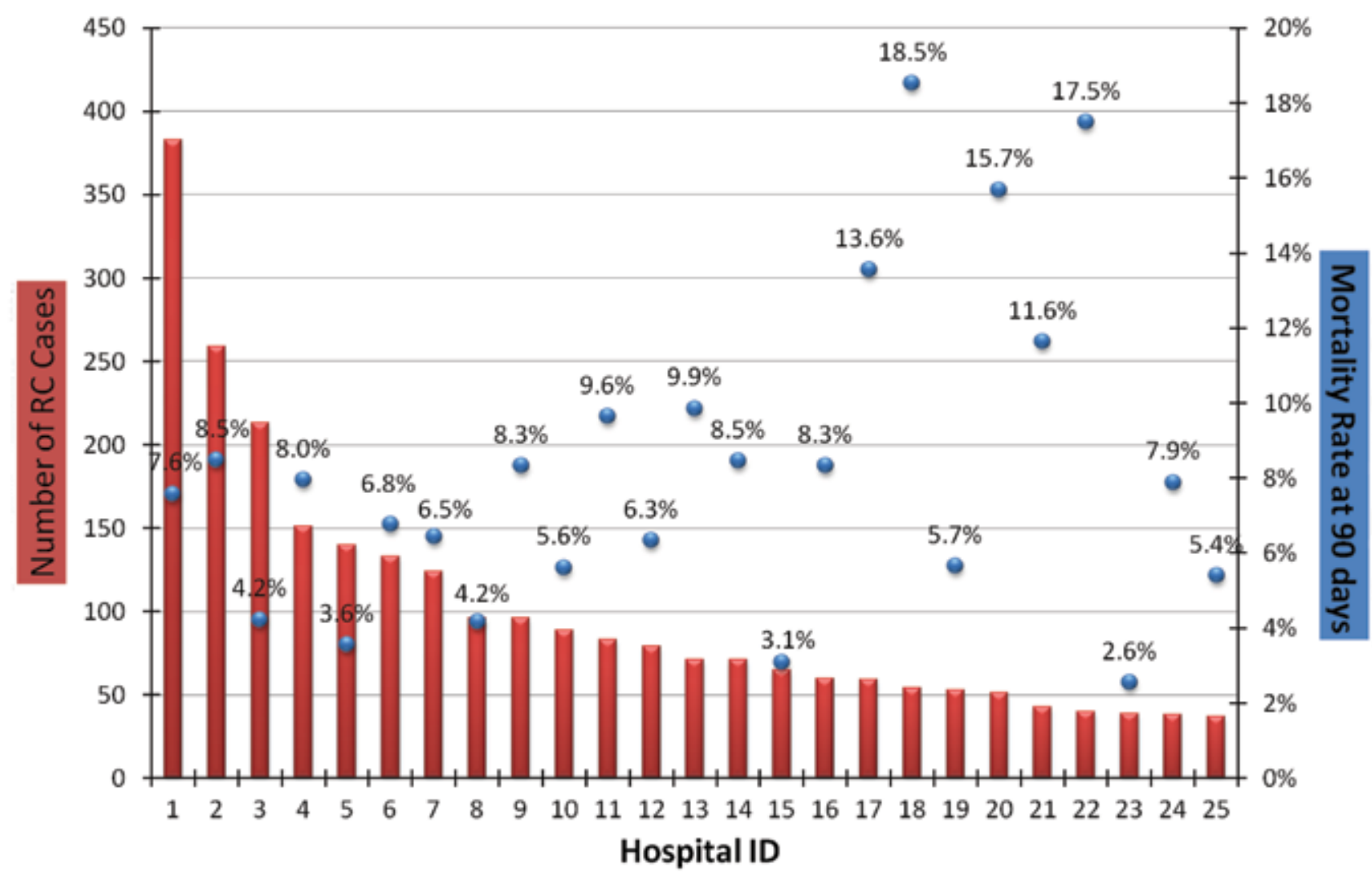

Number of RC cases Mortality rates at 90 days

Fig. 2. Rate of radical cystectomy (RC) and mortality rates at 90 days sorted by hospitals. 


\begin{tabular}{|c|c|c|}
\hline & $\begin{array}{l}\text { Frequency of } \\
\text { RC performed }\end{array}$ & Percent \\
\hline \multicolumn{3}{|l|}{ Type of hospital } \\
\hline Academic $(n=7)$ & 1175 & $42.3 \%$ \\
\hline Community ( $n=41$ ) & 1603 & $57.7 \%$ \\
\hline \multicolumn{3}{|l|}{ Hospital annual RC caseload } \\
\hline Less than $10 \mathrm{RC} /$ year $(\mathrm{n}=39$ ) & 1197 & $42.6 \%$ \\
\hline Between 10-25 RC/year ( $n=7)$ & 953 & $34.3 \%$ \\
\hline More than $25 \mathrm{RC} /$ year ( $\mathrm{n}=2$ ) & 642 & $23.1 \%$ \\
\hline \multicolumn{3}{|l|}{ Hospitals number of beds } \\
\hline Small hospitals $(<200$ beds) $(n=16)$ & 186 & $6.7 \%$ \\
\hline $\begin{array}{l}\text { Medium hospitals (200-500 beds) } \\
(\mathrm{n}=25)\end{array}$ & 702 & $25.3 \%$ \\
\hline Large hospitals ( $>500$ beds) $(n=7)$ & 1890 & $68 \%$ \\
\hline \multicolumn{3}{|l|}{ Surgeon annual $\mathrm{RC}$ caseload } \\
\hline$<5$ RC/year $(n=111)$ & 1922 & $69.2 \%$ \\
\hline$\geq 5 \mathrm{RC} /$ year $(\mathrm{n}=11)$ & 856 & $30.8 \%$ \\
\hline
\end{tabular}

For the hospital annual RC caseload, $23.1 \%(n=642)$ of cases had their RC done in hospitals with more than $25 \mathrm{RC} /$ year (2 hospitals), $34.3 \%(n=953)$ of cases had their RC done in hospitals with caseload between 10-25 RC/year (7 hospitals) and $42.6 \%(n=1183)$ of cases had their RC done in hospitals with less than $10 \mathrm{RC} /$ year (39 hospitals).
For the hospital number of beds variable, small hospitals with less than 200 beds (16 hospitals) performed $6.7 \%$ $(\mathrm{n}=186)$ of cases, medium hospitals with 200-500 beds (25 hospitals) performed $25.3 \%(n=702)$ of cases and large hospitals with more than 500 beds ( 7 hospitals) performed $68 \%(n=1890)$ of cases.

Regarding surgeons' annual RC caseload, $30.8 \%(n=856)$ of patients were operated on by surgeons who perform 5 and more RC/year (11 surgeons), while $69.2 \%(n=1922)$ of patients were operated on by surgeons who perform less than 5 RC/year (111 surgeons).

Results from the multivariate analysis for the possible relation between the observed main outcomes and their potential predictors are shown in Table 5. As expected, when compared to younger patients $(<60)$, all older patients (other age groups) had a greater chance of having at least one postoperative complication (range: $34 \%-66 \%$ ), as well as increased risk of mortality at 30,60 and 90 days. This was especially the case for patients over 75 with at least one postoperative complication (OR 1.66, 95\% Cl: 1.31-2.11), Gl tract complications (OR 1.76, 95\% Cl: 1.03-3.01), wound complications (OR 2.34, 95\% Cl: 1.36-4.04), mortality at 30 days (OR 3.61, 95\% Cl: 1.63-7.97), mortality at 60 days (OR 5.12, 95\% Cl: 2.72-9.66) and mortality at 90 days (OR 3.28, 95\% Cl: 2.05-5.26).

For the hospital volume as a predictor of RC outcomes, our results showed that patients who had their RC in large hospitals had a decreased risk of 30-day mortality (OR 0.29,

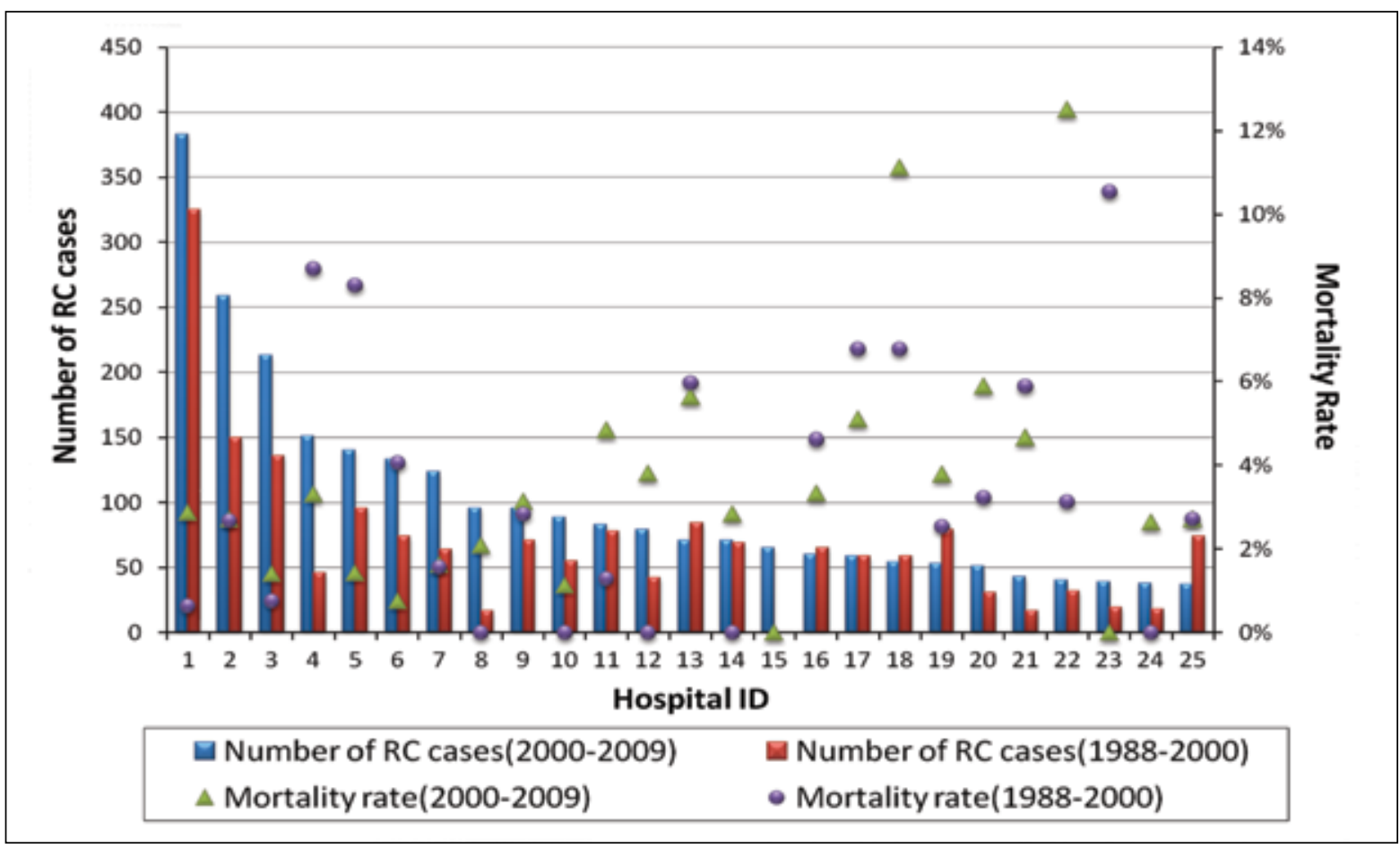

Fig. 3. Rate of radical cystectomy (RC) and 30-day mortality rates sorted by hospitals in the last 2 decades. 


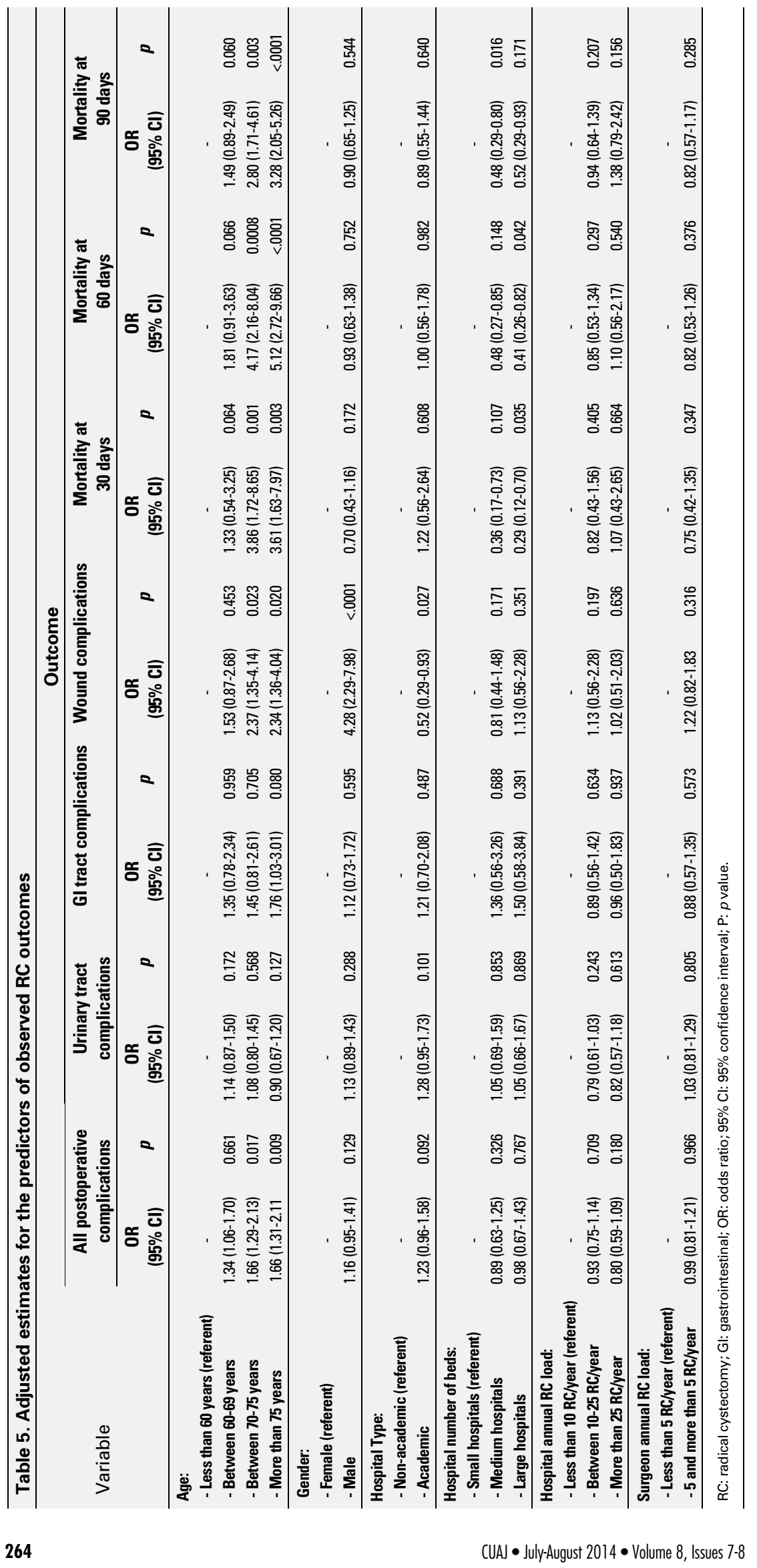




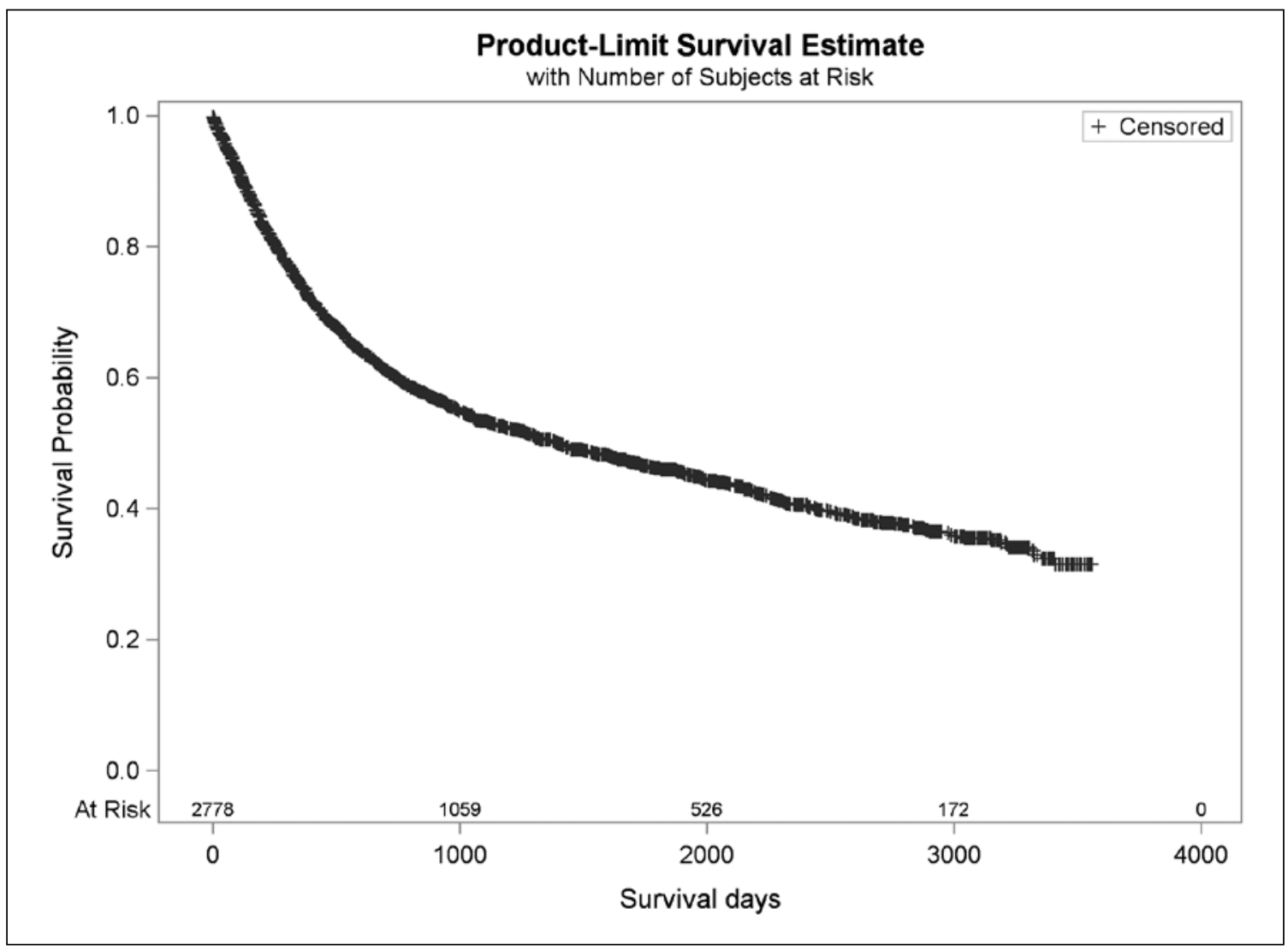

Fig. 4. Cohort overall survival.

95\% Cl: 0.12-0.70), 60-day mortality (OR 0.41, 95\% Cl: 0.26-0.82) and 90-day mortality (OR $0.52,95 \% \mathrm{Cl}: 0.29$ 0.93) when compared to having their RC at smaller hospitals. Academic institutions had better outcomes only in what concerned postoperative wound complications (OR 0.52, 95\% $\mathrm{Cl} ; 0.29-0.93)$. When compared to low annual RC caseload facilities, hospitals with medium and high annual RC caseload did not show statistically significant better outcomes. The relationship between surgeon volume and outcomes showed a weak trend of reduced odds of postoperative mortality at all measured periods (especially mortality at 30 days by $25 \%)$ for the high volume surgeon $(p=0.34)$.

The 5 -year overall survival was $45 \%$, the mean overall survival was 4.7 years (1740 days), and the mortality rate was $49 \%$ (Fig. 4 ).

\section{Discussion}

We present the experience with RC for urinary $\mathrm{BC}$ in Quebec. To our knowledge this is the first study on postoperative complications and mortality after RC for urinary BC for patients in Quebec and provides an opportunity to compare results with other geographic regions in North America and the world.

One of the major limitations of our study is the lack of standardized postoperative complication reporting and the reliance on administrative billing claims for measuring complications. As such, our definitions of complications were restricted to complications that led to billable procedures; therefore, we attempted to follow the methodology described by Martin and colleauges, which includes 10 established basic reporting criteria for reporting complications. ${ }^{13}$

Our reported overall complication rate of $30.6 \%$ includes complications that occurred early as well as late. The 90-day (Clavien grade III-IV) complications rate $(20.9 \%)$ is comparable to those reported from individual centres, which ranged from $10.3 \%$ to $19.7 \%$ for the same grade complications. ${ }^{4,14,15,17}$

Reporting mortality rates using administrative data, as opposed to morbidity measures, is much more reliable. Moreover, it is our opinion that measuring 90-day mortality is more relevant than 30-day mortality since improvements in postoperative care may postpone surgery-related deaths beyond 30 days. ${ }^{16}$ Supporting this point, Shabsigh and colleagues found that $45 \%$ of RC-related deaths occurred between 30 and 90 days and would not have been reported in the traditional 30-day time period. ${ }^{4}$

Our mortality rates at 30,60 and 90 days were $2.8 \%$, $5.3 \%$ and $7.5 \%$, respectively; these rates are considered high when compared with recent literature and reports from around the world. ${ }^{4,17,18}$ In addition, when one compares these rates with a Canadian cohort from academic centres, 
Yafi and colleagues reported rates of $1.3 \%, 2.6 \%$ and $3.2 \%$ at 30, 60 and 90 days, respectively. ${ }^{19}$ In general, the literature contains mainly reports from highly specialized, university affiliated, tertiary or academic centres and therefore it may not be appropriate to compare province-wide results with such centres of excellence. Fortunately, the postoperative mortality rates reported in this study are lower at all time points as compared to our previous study of the period (1998-2000), where the rates were $3.2 \%, 5.7 \%$ and $7.8 \%$ at 30, 60 and 90 days, respectively. ${ }^{20}$ More importantly, our 90-day mortality rates varied widely between hospitals across Quebec, with some hospitals reporting very high mortality rates. Such observations support the recommendation of regionalization of surgical cancer care to centres with better outcomes.

The multivariable analysis did not show an independent relationship between most factors and outcome, except for a protective effect of large hospital size for mortality at 30, 60 and 90 days and a protective effect of academic centres with respect to postoperative wound complications. It is quite possible that the above-mentioned limitations in our dataset precluded identifying an association between volume and outcome. Nevertheless, the relationship between provider volume and outcome in the literature seems to indicate that better outcomes are observed by higher volume providers. ${ }^{10-13,21-23}$

Recently, health policy recommendations (publicly fund$\mathrm{ed}^{24-26}$ or private-based ${ }^{27}$ ) have been proposed to adopt the idea of centralization or regionalization of urologic-oncology care, based on several studies. ${ }^{26,28-30}$ On the other hand, several investigators reported methodological defects in studies supporting higher volume effect after highlighting the limitations of the measures used to assess the volume-outcome relationship. ${ }^{8,31} \mathrm{Also}$, some investigators showed that enhanced methodology could weaken previously reported results and affect final conclusions. ${ }^{32}$

Our study contains several significant limitations including the reliance on administrative data, which lack some clinical information resulting in the inability to perform risk adjustment based on oncologic risk factors (e.g., tumour stage and grade), patient functional status (e.g., comorbid diseases), type of urinary diversion (which can affect postoperative morbidity), as well as the inability to measure disease-specific survival. Nevertheless, it is quite surprising that most hospitals and surgeons in Quebec are unaware of their RC complication and mortality rates. It is important to use this administrative data to inform hospitals and surgeons of their postoperative complications, mortality, and overall survival rates; this knowledge can result in some improvements in outcomes.

\section{Conclusion}

Our study demonstrates that postoperative outcomes after $\mathrm{RC}$ in Quebec vary based on several parameters. Although 30-day postoperative mortality after RC in Quebec appears acceptable, 90-day postoperative mortality rates remain significantly elevated, particularly at some centres, which requires attention. Healthcare authorities should monitor such data regularly and report results to individual hospitals and surgeons to promote transparency and improve quality.

Competing interests: Dr. Zakaria, Dr. Santos, Dr. Dragomir and Dr. Tanguay declare no competing financial or personal interests. Dr. Aprikian is a board observer for Bioniche Inc., a member of the Speakers bureau for Amgen, Abbvie and Astellas. He has also received grants from Amgen, Astellas and Abbvie. Moreover, he has participated in a clinical trial within the past 2 years for Astellas. Dr. Kassouf is an Advisory Board member and a speaker for Amgen and Astellas. He has also received grants and honoraria from these companies. He is currently participating in unpaid clinical trials.

This paper has been peer-reviewed.

\section{References}

1. Siegel R, Naishadham D, Jemal A. Cancer statistics, 2013. CA: A Cancer Journal for Clinicians 2013;63:1130. http://dx.doi.org/10.3322/caac.21166

2. Canadian Cancer Society's Advisory Committee on Cancer Statistics. Canadian Cancer Statistics 2013. Toronto, ON: Canadian Cancer Society; 2013.

3. Meller AE, Nesrallah U, Dall'Oglio MF, et al. Complications in radical cystectomy performed at a teaching hospital. Int Braz J Urol 2002;28:522-5.

4. Shabsigh A, Korets R, Vora KC, et al. Defining early morbidity of radical cystectomy for patients with bladder cancer using a standardized reporting methodology. Eur Urol 2009;55:164-76. http://dx.doi. org/10.1016/j.eururo.2008.07.031

5. Novotny V, Hakenberg OW, Wiessner D, et al. Perioperative complications of radical cystectomy in a contemporary series. Eur Urol 2007;51:397-402. http://dx.doi.org/10.1016/i.eururo.2006.06.014

6. Chahal R, Sundaram SK, Iddenden R, et al. A study of the morbidity, mortality and long-term survival following radical cystectomy and radical radiotherapy in the treatment of invasive bladder cancer in Yorkshire. Eur Urol 2003;43:246-57. http://dx.doi.org/10.1016/S0302-2838(02)00581-X

7. Cooperberg MR, Konety BR. Quality of care indicators for radical cystectomy. From: Current Clinical Urology: Bladder Cancer. C.T. Lee, D.P. Wood, editors. Humana Press; 2010:177-86.

8. Halm EA, Lee C, Chassin MR. Is volume related to outcome in health care? A systematic review and methodologic critique of the literature. Ann Intern Med 2002;137:511-20. http://dx.doi.org/10.7326/00034819-137-6-200209170-00012

9. Barbieri CE, Lee B, Cookson MS, et al. Association of procedure volume with radical cystectomy outcomes in a nationwide database. J Urol 2007;178:1418-22. http://dx.doi.org/10.1016/i.juro.2007.05.156

10. Gilbert SM, Dunn RL, Miller DC, et al. Mortality after urologic cancer surgery: impact of non-index case volume. Urology 2008;71:906-10. http://dx.doi.org/10.1016/i.urology.2007.12.035

11. Birkmeyer JD, Sun Y, Wong SL, et al. Hospital volume and late survival after cancer surgery. Ann Surg 2007;245:777-83. http://dx.doi.org/10.1097/01.sla.0000252402.33814.dd

12. Goossens-Laan CA, Visser 0 , Wouters MW, et al. Variations in treatment policies and outcome for bladder cancer in the Netherlands. Eur J Surg Oncol 2010;36:S100-7. http://dx.doi.org/10.1016/i. ejso.2010.06.003

13. Martin RC 2nd, Brennan MF, Jaques DP. Quality of complication reporting in the surgical literature. Ann Surg 2002;235:803-13. http://dx.doi.org/10.1097/00000658-200206000-00007

14. Hautmann RE, de Petriconi RC, Volkmer BG. Lessons learned from 1,000 neobladders: The 90-day complication rate. J Urol 2010;184:990-4. http://dx.doi.org/10.1016/i.juro.2010.05.037 
15. Novara $G$, De Marco V , Aragona M, et al. Complications and mortality after radical cystectomy for bladder transitional cell cancer. J Urol 2009;182:914-21. http://dx.doi.org/10.1016/i.juro.2009.05.032

16. Takada N, Abe T, Shinohara N, et al. Peri-operative morbidity and mortality related to radical cystectomy: A multi-institutional retrospective study in Japan. BJU Int 2012;110:E756-64. http://dx.doi. org/10.1111/i.1464-410X.2012.11609.x

17. Liedberg F. Early complications and morbidity of radical cystectomy. Eur Urol Suppl 2010;9:25-30.

18. Isbarn H, Jeldres C, Zini L, et al. A population based assessment of perioperative mortality after cystectomy for bladder cancer. J Urol 2009;182:70-7. http://dx.doi.org/10.1016/i.juro.2009.02.120

19. Yafi FA, Aprikian AG, Chin JL, et al. Contemporary outcomes of 2287 patients with bladder cancer who were treated with radical cystectomy: A Canadian multicentre experience. BJU Int 2011;108:539-45. http://dx.doi.org/10.1111/i.1464-410X.2010.09912.x

20. Fahmy N, Jeyaganth S, Mahmud S, et al. Mortality after radical cystectomy in the province of Quebec Paper presented at: Annual Meeting of the Quebec Urological Association; 2006; Montreal, Quebec.

21. Konety BR, Dhawan V, Allareddy V, et al. Impact of hospital and surgeon volume on in-hospital mortality from radical cystectomy: Data from the health care utilization project. J Urol 2005; 173:1695-700. http://dx.doi.org/10.1097/01.ju.0000154638.61621.03

22. Birkmeyer JD, Stukel TA, Siewers AE, et al. Surgeon volume and operative mortality in the United States. N Engl J Med 2003;349:2117-27. http://dx.doi.org/10.1056/NEJMsa035205

23. Konety BR, Allareddy V, Herr H. Complications after radical cystectomy: Analysis of population-based data. Urology 2006;68:58-64. http://dx.doi.org/10.1016/i.urology.2006.01.051

24. Goossens-Laan CA, Visser 0 , Hulshof $M C$, et al. Survival after treatment for carcinoma invading bladder muscle: A Dutch population-based study on the impact of hospital volume. BJU Int 2012;110:226-32. http://dx.doi.org/10.1111/i.1464-410X.2011.10694.x
25. Mayer EK, Bottle A, Darzi AW, et al. The volume mortality relation for radical cystectomy in England: Retrospective analysis of hospital episode statistics. BMJ 2010;340:c1 128. http://dx.doi.org/10.1136/ bmi.cl 128

26. Birkmeyer JD, Siewers AE, Finlayson EVA, et al. Hospital volume and surgical mortality in the United States. N Engl J Med 2002;346:1128-37. http://dx.doi.org/10.1056/NEJMsa012337

27. Milstein A, Galvin RS, Delbanco SF, et al. Improving the safety of health care: the leapfrog initiative. Eff Clin Pract 2000;3:313-6.

28. Barocas DA, Mitchell R, Chang SS, et al. Impact of surgeon and hospital volume on outcomes of radical prostatectomy. Urol Oncol 2010;28:243-50. http://dx.doi.org/10.1016/i.urolonc.2009.03.001

29. Begg CB, Cramer LD, Hoskins WJ, et al. Impact of hospital volume on operative mortality for major cancer surgery. JAMA 1998;280:1747-51. http://dx.doi.org/10.1001/jama.280.20.1747

30. Birkmeyer JD, Sun Y, Wong SL, et al. Hospital volume and late survival after cancer surgery. Ann Surg 2007;245:777-83. http://dx.doi.org/10.1097/01.sla.0000252402.33814.dd

31. Christian CK, Gustafson ML, Betensky RA, et al. The volume outcome relationship: Don't believe everything you see. World J Surg 2005;29:1241-4. http://dx.doi.org/10.1007/s00268-005-7993-8

32. Panageas KS, Schrag D, Riedel E, et al. The effect of clustering of outcomes on the association of procedure volume and surgical outcomes. Ann Intern Med 2003;139:658-65. http://dx.doi.org/10.7326/00034819-139-8-200310210-00009

Correspondence: Dr. Armen G. Aprikian, Division of Urology, McGill University, Montreal General Hospital, 1650 Cedar Avenue, L8-309, Montreal, QC H3G 1A4; fax: 514-934-8297; armen.aprikian@muhc.mcgill.ca 